\title{
Rapid population declines of Himalayan Griffon Gyps himalayensis in Upper Mustang, Nepal
}

\author{
RAJU ACHARYA, RICHARD CUTHBERT, HEM SAGAR BARAL and \\ KARAN BAHADUR SHAH
}

\section{Summary}

The population collapse of resident Gyps vulture species in South Asia, caused by the use of a veterinary drug diclofenac, has highlighted an urgent need to monitor numbers of other vulture species in the region. This study assessed population trends of Himalayan Griffon Gyps himalayensis in the mountainous region of Upper Mustang, Nepal, which is an important breeding area for the species. Vultures were surveyed in 2002, 2004 and 2005 by recording the number of birds sighted along $188 \mathrm{~km}$ of transects, and observing numbers of birds at breeding colonies. The number of birds recorded per day and per kilometre of transect declined by $67 \%$ and $70 \%$ respectively over the period of study. The number of active nests declined by $84 \%$ from 2002 to 2005. The veterinary drug diclofenac was available in pharmacies in the Mustang region. Young Himalayan Griffons, which migrate to the lowland areas of Nepal and, in increasing numbers to India, are highly likely to be subject to diclofenac poisoning. If this rate of population decline occurs throughout the Himalayan region, the conservation status of the species will need to be urgently reassessed.

\section{Introduction}

Populations of three resident species of Gyps vulture, Oriental White-backed Vulture G. bengalensis, Long-billed Vulture G. indicus and Slender-billed Vulture G. tenuirostris have collapsed in South Asia in the last decade, and they are now classed as 'Critically Endangered' (IUCN 2007, Vulture Rescue 2007). The main cause of the declines is the non-steroidal antiinflammatory drug (NSAID) diclofenac, which is commonly used to treat pain and inflammation in livestock in India, Pakistan and Nepal (Green et al. 2004, Oaks et al. 2004, Shultz et al. 2004). Vultures are exposed to diclofenac when they feed on carcasses of livestock that were dosed with the drug shortly before death, and birds die from kidney failure within a few days of exposure (Oaks et al. 2004, Swan et al. 2006). It is unknown if diclofenac is affecting populations of other vulture species and scavenging birds in the region, but numbers of Red-headed Vulture Sarcogyps calvus and Egyptian Vulture Neophron percnopterus have recently undergone rapid declines in India (Cuthbert et al. 2006) and studies have pointed out that not only diclofenac, but also some other NSAIDs are harmful to vultures and other scavenging birds (Cuthbert et al. 2007).

Within Nepal, research and monitoring of vulture species has been undertaken in lowland areas and has revealed similar declines (in excess of $90 \%$ ) in populations of Oriental Whitebacked and Slender-billed Vultures (Baral et al. 2002a, 2004), as well as the widespread use of diclofenac (H.S. Baral pers. obs.) and the presence of the drug in vulture carcasses (Shultz et al. 2004). Populations of both lowland species have continued to decline and they are now almost absent or extinct from eastern areas of the country as breeding birds (H.S. Baral pers. obs.). While a grave conservation situation is clear for lowland species, research in high altitude areas of Nepal has been lacking. Nepal holds important breeding populations of the Himalayan 
Griffon G. himalayensis which is found elsewhere in Pakistan, India, the Peoples Republic of China, Myanmar and possibly the northern part of Russia (Del Hoyo et al. 1994). Currently the Himalayan Griffon is not believed to approach the thresholds for the population decline criterion of the IUCN Red List and is evaluated as 'Least Concern' (IUCN 2007) and its status has been described as "common" to "fairly common" in Nepal (Grimmett et al. 2000, Baral et al. 2002b).

The effect of diclofenac on Himalayan Griffon is predicted to be as lethal as on the lowland species of Gyps vultures (Swan et al. 2006). Since livestock husbandry is an integral part of Nepal's mountain ecosystems there may also be diclofenac use and contamination of carcasses in high altitude areas of the country. As a consequence, there is an obvious need to monitor the population of Himalayan Griffons and ascertain the use of diclofenac in the Himalayan regions of Nepal. This study aims to fill this gap, and to set out baseline data on population trends of Himalayan Griffon within Upper Mustang, Nepal.

\section{Methods}

\section{Study Area}

The study was conducted in Upper Mustang, an area of 2,567 $\mathrm{km}^{2}$, which covers the northern half of Mustang District (Ale 2002; Figure 1). The study area belongs to the arid, transHimalayan zone of the Annapurna Conservation Area (ACA) (BCDP 1994) which supports a unique ecosystem (Suwal 2003). The zone receives an average rainfall of $132 \mathrm{~mm}$ per annum and is drained by the Kaligandaki River and its numerous tributaries. Upper Mustang is overseen by seven Village Development Committees - (Chuksang, Ghemi, Tsarang, Lomanthang, Chhosyar, Chhunup and Surkhang) and has up to 33 human settlements containing around 6,100 people (Shah 2001). These people practise a combination of livestock farming, agriculture and seasonal trade in winter. The Upper Mustang Biodiversity Conservation Project has been implemented to restore the ecology and economy through the sustainable use of its biodiversity (Suwal 2003).

\section{Survey methods}

Himalayan Griffons were surveyed along transects for 24, 22 and 22 days in 2002, 2004 and 2005 respectively. The surveys were carried out between July and September (Table 1 ), the summer months when Himalayan Griffon are breeding and when resident birds are most likely to be observed. Two main data collection methods were used: 1) transects were walked through the region and all vultures recorded; and 2) all nesting sites in areas of suitable habitat were scanned, with additional incidental observation of vultures at carcasses and human sky-burial sites.

Transects were walked along the main trails used by local people in the region. These trails were selected for their relative ease of access and because they covered a representative area of Upper Mustang where Himalayan Griffons were known to occur. Four main transects totalling $188 \mathrm{~km}$ in length were covered in each survey year. Those transects were located north-south from Jomsom to Nichung, Lomanthang to Samjung and back, and Lomanthang to Jomsom (approximately 89, 18 and $64 \mathrm{~km}$ respectively, and taking 16, one and four successive days of walking in 2002 and 15, one and four successive days of walking in 2004 and 2005) and east-west from Lomanthang to Yara and back ( $17 \mathrm{~km}$ over three days in 2002 and two days in the rest of the year). The length of transects covered per day varied depending upon the settlement, altitude and climate. Transects were walked from o8hoo to 17 hoo of each survey day, when Himalayan Griffon vultures were active and soaring in search of food. All vultures observed up to $500 \mathrm{~m}$ on each side of the transect were identified and recorded. Vultures observed beyond $500 \mathrm{~m}$ were ignored in each survey year. Distance was based on ocular estimation and repeated in each survey year. To make a more precise estimate of distance, a distance of $500 \mathrm{~m}$ was marked out on the ground prior to each survey, to familiarize the observer with the width of observation. There was 
Upper Mustang Vulture Survey Route (2002-2005)

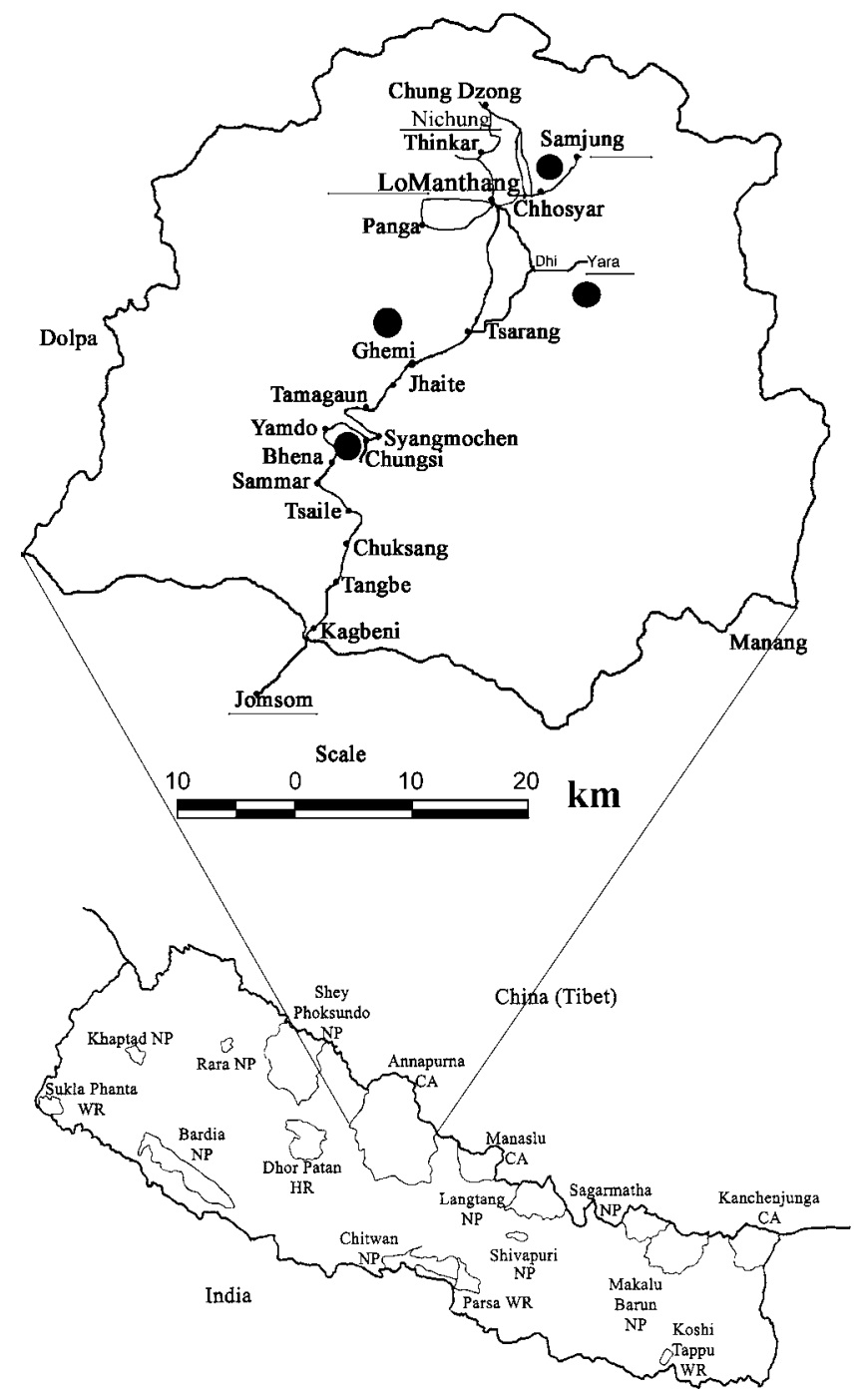

Figure 1. Locations of the transect survey routes and breeding colonies in Upper Mustang district, Nepal. - Indicates the major survey route and $\bullet$ indicates the breeding colonies of Himalayan Griffons Source: Baral and Heinen 2007, NTNC/ACAP.

some possibility of double counting individual birds, either on the same day or succeeding days. However, the same bias is present in each year of the study and should still allow reliable estimation of population trends.

An area of approximately $400 \mathrm{~km}^{2}$ of suitable habitat (e.g. steep rocky cliffs and gorges where Himalayan Griffon are likely to nest) was scanned from transect routes and vantage points to locate and identify nesting sites of the species. Possible sites were also located on the basis of information from local people and published sources. Survey efforts for nests observation were 
Table 1 . Dates, duration, numbers of Himalayan Griffon and detection frequency over $188 \mathrm{~km}$ of transect in Upper Mustang.

\begin{tabular}{llll}
\hline & 2002 & 2004 & 2005 \\
\hline Dates & $\begin{array}{l}12 \text { August to } 9 \\
\text { September }\end{array}$ & $\begin{array}{l}13 \text { July to } 7 \\
\text { August }\end{array}$ & $\begin{array}{l}\text { 26 August to 18 } \\
\text { September }\end{array}$ \\
$\begin{array}{l}\text { Duration } \\
\text { Total recorded (transect, }\end{array}$ & 333 & 22 days & 235 \\
baiting and carcasses) & & & 185 \\
Number at baiting sites & - & 62 & 82 \\
Number at carcasses & 110 & 28 & 35 \\
$\begin{array}{l}\text { Birds recorded along } \\
\text { the transects }\end{array}$ & 223 & 145 & 68 \\
$\begin{array}{l}\text { Birds day } \\
\text { Birds } \mathrm{km}^{-2} \text { (transect) }\end{array}$ & 9.29 & 6.59 & 3.09 \\
\hline
\end{tabular}

increased over the course of the study, with an additional nesting area being visited in 2005. The nests were classified as 'occupied' on the basis of the presence of nesting birds or fresh white droppings on the nest rim and nesting ledge, or fresh droppings on the rock cliffs underneath the nesting sites (Postupalsky 1974). Nests with old droppings of an off-white or brown appearance were categorized as 'unoccupied'. The occupied nests were assumed to hold one pair of vultures. 'Active' nest refers to any nest where young ones were present at the time of the study.

Data on the availability and use of veterinary medicines, pesticides, fungicides and insecticides were collected from the District Livestock Service Centre, the District Agriculture Development Centre and from three veterinary/agricultural service shops at Jomsom, the main town and headquarters of Mustang district.

\section{Results}

\section{Transect surveys}

Totals of 223, 145 and 68 Himalayan Griffons were recorded along the transects in the three respective years of the surveys (Table 1 ), with annual totals including birds recorded at carcasses or at burial sites of 333, 235 and 195, respectively. Between 2002 and 2005, the number of birds recorded per day and number of birds recorded per kilometre of transect declined by $67 \%$ and $70 \%$ respectively, which is equivalent to a decline rate of $31-33 \%$ per year, if declines have been constant over the four-year period. The numbers of vultures recorded on transect 1 (Jomsom to Nichung, $89 \mathrm{~km}$ in length) and transect 4 (Lomanthang- Yara-Lomanthang, $17 \mathrm{~km}$ in length), showed $73 \%$ and $94 \%$ declines respectively, over the period from 2002 to 2005 (Table 2). An observed decline of $54 \%$ was recorded along transect 2 (Lomanthang-Samjung-Lomanthang, $18 \mathrm{~km}$ )

Table 2. Number of Himalayan Griffons recorded on the four transects.

\begin{tabular}{lllll}
\hline & $\begin{array}{l}\text { Transect } 1 \\
\text { (Jomsom to } \\
\text { Nichung) } \\
(89 \mathrm{~km})\end{array}$ & $\begin{array}{l}\text { Transect 2 } \\
\text { (Lomanthang- } \\
\text { Samjung- } \\
\text { Lomanthang) } \\
(18 \mathrm{~km})\end{array}$ & $\begin{array}{l}\text { Transect 3 } \\
\text { (Lomanthang to } \\
\text { Jomsom) } \\
(64 \mathrm{~km})\end{array}$ & $\begin{array}{l}\text { Transect 4 } \\
\text { (Lomanthang-Yara- } \\
\text { Lomanthang) } \\
(17 \mathrm{~km})\end{array}$ \\
\hline Year & & 33 & 9 & 16 \\
2002 & 165 & 4 & 4 & 7 \\
2004 & 130 & 14 & 9 & 1 \\
\hline 2005 & 44 & & & \\
\hline
\end{tabular}


over the same period, however almost no change was observed on transect 3 (Lomanthang to Jomsom, $17 \mathrm{~km}$ ) where low numbers of vultures were observed in all three years of the survey (Table 2). Transects 2 and 3 are of the shortest distance and duration and consequently may be subject to more random variation than the longer sections and the whole route.

\section{Nesting sites}

In total, 58 and 61 Himalayan Griffon nests were observed in caves on vertical cliffs in 2004 and 2005 respectively, although survey effort was higher in 2005, with an additional four nests (one active and three unoccupied) encountered in a new area in 2005. At nest sites that were fully visible, birds were not observed to use nesting materials of any kind. In 2005, nine nests (15\%) were active, 16 nests (26\%) were occupied and 36 nests (59\%) were unoccupied. Similarly, in 2004 , eight nests (14\%) were active, 17 nests $(29 \%)$ were occupied and 33 nests $(57 \%)$ were unoccupied. Assuming that all active nests and all occupied nests with fresh faeces contained two members of a pair, then the number of nests recorded in 2004 and 2005 represents a population of around 50 adult birds. New and active nesting sites of Himalayan Griffon were observed in Chungshi and Samjung areas in 2005 due to the wider coverage of the survey in 2005 than in 2004. Two nesting colonies (Ghemi and Chosyar) were monitored in all years of this study, with a third nesting colony (Chungshi) monitored in 2004 and 2005 (Table 3). The number of active nests at Ghemi and Choysar declined by 100\% and 75\% respectively from 2002 until 2004, with evidence of a smaller decline $(27 \%)$ at Chungshi from 2004 to 2005. Numbers at Chosyar appear to be stable (but very low, four and six respectively) in the last two years of survey. Combining both Ghemi and Chosyar colonies, nest numbers have declined by $84 \%$ from 2002 to 2005 (Table 3).

\section{Veterinary and agricultural compounds}

In Mustang district, the District Livestock Development Service and three other shops in the Jomsom area were found to be distributing and selling veterinary medicines. In total, 47 products were recorded, the most common being anti-helmenthic medicines for the treatment of internal (six compounds) and external (three compounds) parasites; antibiotics (six), and antiseptics (three). Only one general pain killer and anti-inflammatory drug for the treatment of livestock was found, the NSAID voviram bolus, which contains diclofenac sodium as the active ingredient.

In Mustang district, the use of agricultural chemicals including pesticides, insecticides and fungicides started in 1998 and the practice still continues. Altogether 5,623 litres of diesel and 2.57 metric tons of other pesticides, insecticides, and fungicides have been distributed between 1998 and 2004. Of these, diesel oil (used as a herbicide), dimethoate, ravistin, zinc phosphitezon and diethane- 45 are most commonly used in the Mustang region.

\section{Discussion}

The results of this study indicate that there have been substantial declines in the resident population of Himalayan Griffons in upper Mustang of Nepal. While the study period was

Table 3. Number of Himalayan Griffons recorded at colonial nest sites in Upper Mustang.

\begin{tabular}{llll}
\hline Year & \multicolumn{3}{c}{ Site } \\
\cline { 2 - 4 } & Ghemi & Chosyar & Chungshi \\
\hline 2002 & 22 & 16 & $*$ \\
2004 & 0 & 4 & 15 \\
2005 & 0 & 6 & 11 \\
\hline
\end{tabular}

${ }^{*}$ Not surveyed in 2002 
limited in duration (from 2002 to 2005), evidence for declines comes from the decrease in vultures seen along transects walked across the region and from repeated counts of nest numbers at monitored breeding sites (Figure 2). Declines in breeding numbers were found at all three areas monitored, with no nests recorded at one site (Ghemi) in 2004 and 2005, despite the presence of 22 nesting bird in 2002. Similarly, no nesting birds were recorded in any year of the survey at a fourth breeding colony (Yara cave) despite the presence of breeding birds observed here during 1993 to 1997 (R. Acharya pers. obs.). Over the same time period the number of birds recorded along $188 \mathrm{~km}$ of transect through the region declined by $70 \%$. These observation from four breeding colonies and transects indicate a substantial decline of the species, confirming the suggestions made by Baral et al. (2002b).

While evidence from transects and nesting colonies has indicated a significant decline, incidental counts of vultures attending sky burial sites and carcasses have shown more stable numbers. Between 54 and 70 vultures (average 61) were in attendance at human sky burial sites (Box I) between October 2003 and February 2005. Similar numbers (62 and 82) were recorded in 2004 and 2005 for goat carcasses used as bait at the same sky burial site. A total of 110 (with one carcass site), 28 (with three carcass sites) and 35 (with one carcass site) Himalayan Griffons was recorded in 2002, 2004 and 2005 in attendance at livestock carcasses along the transect route. However sample size (only a limited number of feeding events in each year of survey), exact date of baiting, amount of food available, time spent at the site, and other climatic conditions may confound the comparisons. In addition, as feeding events are likely to attract vultures from a very wide area (satellite tagged White-backed Vultures in Pakistan ranged over areas of up to $69,000 \mathrm{~km}^{2}$; Gilbert et al. 2007) they may be less likely to reflect population trends than counts of birds along transect routes and at breeding colonies.

\section{Box 1. Sky burial practices in the study area}

When a local person dies, the lama, the religious leader and respected holy person of the area, decides how to carry out funeral rites. A few specific castes including Bista usually burn a small portion of dead body parts, but the major caste of the area, the Gurung ( $>90 \%$ of the local population) cuts up the corpse into small pieces as offerings to the vultures. The Lama invites the vultures by praying and playing a trumpet or bell. If vultures do not visit the corpse it is believed that the person has committed some great sins during his lifetime. Local Buddhist people believe that the vultures take the soul of dead person to heaven.

The use of pesticides, herbicides, and insecticides was found to be common in Upper Mustang. Pesticides may be lethal to the predators of livestock, which may eventually affect other carrion feeders over the whole of Mustang (Suwal 2003). Although the Annapurna Conservation Area Project (ACAP) gives emphasis to organic farming, the rate of pesticide consumption in the area is actually increasing. A wide range of veterinary medicines was found to be promoted and on sale in Mustang district, including one NSAID for treating livestock that contained diclofenac. The scale of use of this drug in the region is currently unknown. However, given our knowledge of the impact of diclofenac on lowland species of Gyps vultures, we advocate an immediate end to the use of this drug in Mustang and other Himalayan regions, in order to protect Himalayan Griffons. As a result of the recent ban (2006) on the manufacture and import of diclofenac in Nepal (Vulture Rescue 2007), the amount of veterinary diclofenac should become reduced in the region. Promotion of meloxicam, a vulture-safe alternative drug which is as effective as diclofenac for treating livestock (Swan et al. 2006, Swarup et al. 2007) and already manufactured and on sale within Nepal, should be undertaken throughout the country. Mustang's proximity to China and Tibet, where veterinary diclofenac is manufactured, means that controls must also be put in place to ensure that it is not illegally imported into Nepal. Similarly, diclofenac may also reach Nepal from India (BCN unpubl. data). As well as the threat diclofenac presents 


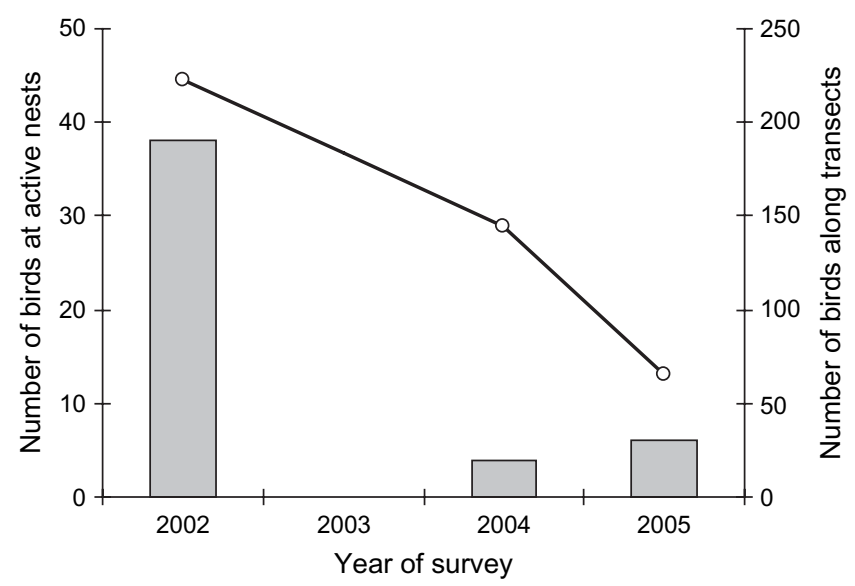

Figure 2. Combined number of Himalayan Griffons recorded at the Ghemi and Chosyar breeding colonies (bars) and total number of Himalayan Griffons (line) recorded flying (excluding sightings at carcasses and burial sites) along $188 \mathrm{~km}$ of transects walked over $22-24$ days in 2002, 2004 and 2005 .

to breeding vultures resident within Mustang, many young Himalayan Griffons descend to lowland Nepal and further south to northern India during winter (Chaudhary and Pariyar 2004, de Roder 1989, Gurung et al. 2004, Cuthbert et al. in prep). Numbers of both Himalayan Griffons and Eurasian Griffons Gyps fulvus have increased nearly threefold in Rajasthan State, northern India, over the period 1995/96-2003 (Chhangani and Mohnot 2004), and increasing numbers are seen further south in India each year (V. Prakash pers. comm.). In these localities, Himalayan Griffons will be exposed to the same risk of diclofenac poisoning as the other three Critically Endangered Gyps species of the Indian subcontinent, and it is likely that the lowlands of Nepal and northern India are acting as a major population sink for the species since the collapse in numbers of resident Gyps species.

In conclusion, this study demonstrates that the number of Himalayan Griffons has substantially decreased in the Mustang region of Nepal. Populations along transects declined by up to $70 \%$ from 2002 to 2005 , at an average decline rate of $30 \%$ a year: a rate of decline comparable with the annual declines of $22 \%$ and $48 \%$ recorded for the now 'Critically Endangered' Longbilled and Oriental White-backed vultures in India (Green et al. 2004). We strongly recommend repeat surveys and population assessments of Himalayan Griffons from Mustang and other areas of Nepal, India and Pakistan along the species' breeding range to determine if this species is declining across its range. If these declines are replicated in other areas of Nepal and throughout the Himalayan region, then the conservation status of the Himalayan Griffon needs to be urgently assessed and immediate steps should be taken to conserve Himalayan Griffons before their population follows the same course as other Gyps vultures in South Asia.

\section{Acknowledgements}

We are most grateful to the National Trust for Nature Conservation/ Annapurna Conservation Area Project (NTNC/ACAP), Nepal, Royal Society for the Protection of Birds (RSPB), UK, the UK Government Darwin Initiative for the Survival of Species, and Bird Conservation Nepal (BCN) for financial supports to carry out the study from 2002-2005. It is our great pleasure to express our eternal gratitude to Carol Inskipp, Rajendra Narshing Suwal, Som Ale, Roshan Sherchan, Ram Chandra Nepal, Dr. Sidhartha Bajra Bajracharya, Binod Basnet, Lizan Kumar Maskey, Nabin Baral, Dr. Purushotam Shrestha, Madhu Chetri, Ramji Acharya, Kajiram 
Adhikari, Basudev Neupane, Hira K.C., Suresh Thapa, Yadav Ghimirey, Surendra Gautam, Ananta Bhandari, Norbu Pasang Gurung, for their professional guidance and valuable suggestion during the entire study period. Last but not the least we would like to thank all the staff of Friends of Nature, NTNC/ACAP Lomanthang, Jomsom, Sikles and people of Upper Mustang who supported us during the entire study period.

\section{References}

Ale, S. B. (Ed) (2002) Upper Mustang biodiversity conservation project status brief (NEP/99/G35; NEP/99/o21). Kathmandu, Nepal: King Mahendra Trust for Nature Conservation.

Baral, H. S., Giri, J. B., Choudhary, H., Basnet, S., Watson, R. and Virani, M. (2002a) Survey of Himalayan Griffon Gyps himalayensis in the Nepalese Himalayas, final report. Boise, Idaho, USA: The Peregrine Fund.

Baral, H. S., Poudel, N., Giri, J. B., Watson, R. and Virani, M. (2002b) Study of vultures in lowland Nepal, final report. Boise, Idaho, USA: The Peregrine Fund.

Baral, H. S., Giri, J. B. and Virani, M. Z. (2004) On the decline of Oriental White-backed vultures Gyps bengalensis in lowland Nepal. Pp. 215-219 in R. D. Chancellor and B.-U. Meyburg, eds. Raptors worldwide. Proceedings of the $6^{\text {th }}$ world conference on birds of prey and owls. Budapest, Hungary: WWGBP and MME (BirdLife Hungary).

Baral, N. and Heinen, J. T. (2007) Resources use, conservation attitudes, management intervention and park-people relations in the Western Terai landscape of Nepal. Environ. Conserv. 34: 64-72.

BCDP. (1994) Biodiversity conservation data project: final report. Kathmandu, Nepal: King Mahendra Trust for Nature Conservation.

Chhangani, A. K. and Mohnot, S. M. (2004) Is diclofenac the only cause of vulture decline? Current Sci. 87: 1496-1497.

Chaudhary, J. and Pariyar, H. 2004. Vulture sighting in Pokhara Valley. Danphe 13: 8.

Cuthbert, R., Green, R. E., Ranade, S., Saravanan, S. S. Pain, Prakash, V. \& Cunningham, A. A. (2006) Rapid population declines of Egyptian Vulture Neophron percnopterus and Red-headed Vulture Sarcogyps calvus in India. Anim. Conserv. 9: 349-354.
Cuthbert, R., Parry-Jones, J., Green, R. E. \& Pain, D. J. (2007) NSAIDs and scavenging birds: potential impacts beyond Asia's critically endangered vultures. Biol. Lett. 3: 90-93. Cuthbert, R., Shultz, S., Pain, D. J., Cunningham, A. A., Prakash, V.. (in prep) Long distance migration of Eurasian Griffon (Gyps fulvus) and Himalayan Griffon (Gyps himalayensis) from northern India.

de Roder, F. (1989) The migration of raptors south of Annapurna, Nepal, autumn 1985. Forktail 4: 9-17.

del Hoyo, J., Elliott, A. and Sargatal, J. (eds.) Handbook of the birds of the world. Volume 2. New World vultures to guineafowl. Barcelona, Spain: Lynx Edicions.

Gilbert, M., Watson, W. T., Ahmed, S., Asim, M. and Johnson, J. A. (2007) Vulture restaurants and their role in reducing diclofenac exposure in Asian vultures. Bird Conserv. Internatn. 17: 63-77.

Green, R. E., Newton, I., Shultz, S., Cunningham, A. A., Gilbert, M., Pain, D. J. and Prakash, V. (2004) Diclofenac poisoning as a cause of vulture population declines across the Indian subcontinent. J. Appl. Ecol. 41: 793-800.

Grimmett, R. Inskipp, C. and Inskipp, T. (2000) Birds of Nepal, Helm field guide. Delhi: Oxford University Press.

Gurung, S. B., Gurung, S., Gurung, S. and McCarthy, K. (2004) Autumn 2003 raptor migration in Central Nepal. International Hawkwatcher 9: 12-15.

IUCN 2007. 2007 IUCN Red List of threatened species. www.iucnredlist.org;. Downloaded 12 March 2007.

Oaks, J. L., Gilbert, M., Virani, M. Z., Waston, R. T., Meteyer, C. U., Rideout, B. A., Shivaprasad, H. L., Ahmed, S., Choudhary, M. J. I., Arshad, M., Mahamood, M., Ali, S. and Khan, A. A. (2004) Diclofenac residues as the cause of vulture population decline in Pakistan. Nature 427: 630-633. 
Postupalsky, S. (1974) Raptors reproductive success: some problem with method, criteria and terminology. Pp. 21-3I in F. N. Hamerstrom, Jr., B. E. Harell and R. R. Olendorff, eds. Management of raptors: Proceedings of the conference on raptor conservation techniques. Fort Collins, CO: Raptor Research Foundation (Raptor Research Reports 2).

Shah, K. B. (2001) Upper Mustang biodiversity conservation project. Kathmandu, Nepal: King Mahendra Trust for Nature Conservation. Research Report Series 4.

Shultz, S., Baral, H. S., Charman, S., Cunningham, A., Das, D., Ghalsasi, G. R., Goudar, M. S., Green, R. E., Jones, A., Nighot, P., Pain, D. J. and Prakash, V. (2004) Diclofenac poisoning is widespread in declining vulture populations across the Indian subcontinent. Proc. R. Soc. Lond. B. (Suppl. 6): S458-46o.
Suwal, N. R. (2003) Ornithological survey Upper Mustang, Upper Mustang biodiversity conservation project. Kathmandu, Nepal: King Mahendra Trust for Nature Conservation.

Swan, E. G., Cuthbert, R., Quevedo, M., Green, R. E., Pain, D. J., Bartels, P., Cunningham, A., Duncan, N., Meharg, A. A., Oaks, L., Parry-Jones, J., Shultz, S., Taggart, M. A., Verdoorn, G. and Wolter, K. (2006) Toxicity of diclofenac to Gyps vultures. Biol. Lett.2: 279-282.

Swarup, D., Patra, R. C., Prakash, V., Cuthbert, R., Das, D., Avari, P., Pain, D. J., Green, R. E., Sharma, A. K., Saini, M., Das, D. and Taggart, M. (2007). The safety of meloxicam to critically endangered Gyps vultures and other scavenging birds in India. Anim. Conserv. 10: 192-198.

Vulture Rescue (2007) Drug launched to save Nepal's vultures. http://www.vulturedeclines. org/page42.html, accessed 17 May 2007.

\section{RAJU ACHARYA*}

Coordinator, Biodiversity and Climate Change, Friends of Nature, P.O.Box 23491, Sundhara, Kathmandu, Nepal.

HEM SAGAR BARAL

Chief Executive Officer, Bird Conservation Nepal, P.O. Box 12465, Kathmandu, Nepal.

\section{RICHARD CUTHBERT}

Royal Society for the Protection of Birds, The Lodge, Sandy, Bedfordshire SG19 2DL, UK.

\section{KARAN BAHADUR SHAH}

Natural History Museum, Tribhuvan University, Swayambhu, Kathmandu, Nepal.

*Author for correspondence; e-mail: rajuhugu_13@yahoo.com 